\title{
PHYSICAL AND HEALTH EDUCATION AGAINST CHILDHOOD OBESITY IN ROMANIA
}

\author{
Cristiana Lucreția POP ${ }^{1}$
}

\begin{abstract}
Our daily life combines an increasingly sedentary lifestyle with energy dense foods consumption. Adding increasing energy intake to decreasing energy expenditure results in body fat deposits. Depending on the amount of fat stored in the body and calculating Body Mass Index (BMI) categories of health risk are classified in overweight or pre-obesity, obesity and morbid obesity. Based on previous reports this article drew attention to the increasing extent of obesity in Romanian children. Further preventive measures in the physical and health education area were proposed.
\end{abstract}

Keywords: overweight, lifestyle, physical activity, parental responsibility.

JEL classification: I10, I19

DOI: $10.24818 /$ mrt.20.11.02.03

\section{Introduction}

Obesity is a global challenge for public health in the 21-st century. The number of children being on risk for obesity increased significantly not only in developed countries, were the abundance can explain de over consumption, but also in developing countries. The phenomena common factors are dietary intake, physical activity, and sedentary behavior, moderated by age, gender, and family lifestyle [1]. Environmental factors such as school policies, demographics, and parents' education level influence further children eating and activity behaviors.

This article objective is to discuss the obesity trend and to explore the childhood obesity perspective in Romania. The argument is based on secondary data collected and presented in Eurostat reports about the incidence of obesity in European Union countries and in the national report about childhood obesity part of the European Childhood Obesity Surveillance Initiative. Also, primary data were presented as an argument in support of measures to control the phenomenon.

\section{Data}

\footnotetext{
${ }^{1}$ The Bucharest University of Economic Studies, crispotir@yahoo.com
} 
According to a Eurostat report on obesity in EU member states (Eurostat, 2011), for both women and men aged 18 years and over the lowest incidence of obesity in 2008/9 was observed in Romania (8.0\% for women and $7.6 \%$ for men) [2]. In the 2016 report the percentage for Romania increased to 9,4 (9,7\% for women and 9,1\% for men); remaining the lowest in the EU countries. However, the European Union average was in 2011 16.6\% in terms of adult obese people, but in 2014 the share of obese adults was slightly lower: 15.9\%. The important figure in this statistic is the percentage of overweight and obese people comparing to normal and underweight persons: $48,4 \%$ to $51,6 \%$ in favor for those with extra-weight [3]. More than half of EU adult citizen are to heavy comparing with the reference data meaning a Body Mass Index (BMI) greater than $25 \mathrm{~kg} / \mathrm{m}^{2}$.

Healthy lifestyle habits usually run in families. If adults gain weight at national scales the children and youngsters are following the example. According to a Romanian Public Health Institute report published in 2008, from 2000 until 2008 the number of obese children starting primary school has doubled (from 1.8\% to $3.6 \%$ ). Pre-obese and obese children have little chances to have a normal weight in future, in that $80 \%$ of them will remain overweight and end up as obese teenagers and adults. The European Childhood Obesity Surveillance Initiative reported in 2017 for Romania a significant higher share of obese children of 7 years of age: $14,9 \%$ for boys and 10,7\% for girls, with an average of 12,8\% [4]. The following graph illustrates how obesity aggressively spreads at a young age:

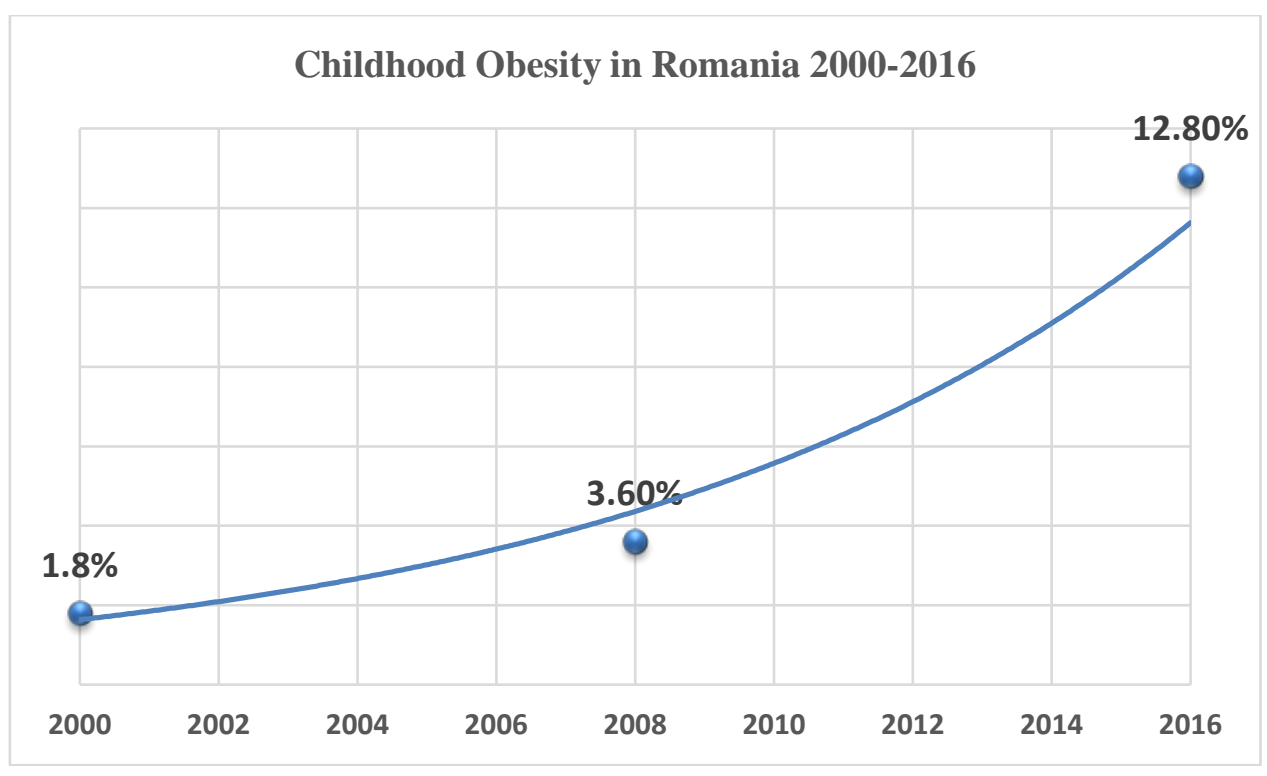

Vol XI • Nr. 2 • 2019 
This data is confirmed by our research on samples of university students. Results shows an increase in overweight and obese percentage in 20 years of age students' population from 2,5\% in 2000 to $9,1 \%$ in $2014(\mathrm{p}<0,01)$ [5] and then to $11,25 \%$ in 2016 [6]. This is the age group 18 to 24 years whit the lowest shares of overweight population in the EU in 2014. The body fat percentage is naturally growing with age. Consequently, this share of pre-obese young people will increase in adulthood. Following this trend, we can easily predict a significantly larger number of overweight young people, when the cohort of 7 years old children will enter in universities, in approximately eight to ten years from now on.

\section{Discussion}

Obesity and overweight are usually associated with a wide range of other medical conditions, physical limitations, and psychological vulnerabilities which become a burden for the family and social insurance budget. Optimal allocation of resources for screening, and development of cost-effective strategies requires accurate assessment of the absolute and relative burden of obesity and associated disease in each region and eventually at country level. This approach could be informative to policy makers when assessing lifelong implications and the loss of healthy and active years for obese people.

There are also a set of preventive measures that could be implemented in schools and families from early ages aiming a healthy development and grow for our children and teenagers. Those rules are not costly, but are undermined by mentalities, cosiness and lately by digital lifestyle. Parental responsibility plays a key role in this preventive plan because primarily children acquire nurturing habits in families. A counterproductive aspect in parenting is a persistence of oversimplistic thinking about children body weight regulation. Parents may deny that there is a problem and may be unwilling to change family eating patterns or sedentary behaviours. Health education, for both parts pupils and parents, is the missing link between what some parents perceived as their child well-being and what the sustainable lifestyle really is. As time as children have not discernment, parents have full responsibility for their wellbeing and the success of failure regarding a healthy and active life.

Physical activity is fundamentally important for the maintenance of life functions; it is an essential mean of being healthy, as it has a proven protective role against the development of metabolic and skeletal disorders, cardiovascular disease, type 2 diabetes, or psychological vulnerabilities (low self-esteem, bulling, depression, social reluctant attitudes). Research observed that proper physical activity may increase the perception of well-being and own body appreciation [7]. However, children and youngsters facing weight challenges may face difficulties to meet at least 30 minutes of moderate-intensity activity or the physical education requirements corresponding their age. This unbalanced relationship between energy intake and energy spent in low levels of active leisure activities may create 
a vicious circle [8]. Therefor it may be the time of thinking PE in ergonomic terms oriented towards efficient programs dedicated to the increasing number of children with extra weight.

In active plays the competition and hierarchy are inherent, but in same time children are motivated by success and positive feed-back. Achievements and successes in physical activities are obvious contributors for pupil's self-esteem and self-confidence, boosting their enthusiasm and energy [9]. Therefore, a positive, encouraging and supportive working atmosphere will include overweight children easier in playing groups and teams. A special attention is required in establishing an optimal balance between effort and recovery brakes and in respecting the accessibility principle. Eventually physical education mission is to enable students of all sizes and possibilities with meaningful skills, knowledge and physical experiences.

In a study on a sample of overweight and obese young women, university students, was observed that only physical exercise systematic practice is insufficient for weight loss [10]. A healthy diet coupled with systematic physical activity may have better effects in weight management. A help at hand for a healthy diet can be given by technology, because nowadays technology shapes how individuals think and act in society.

Smartphones applications with 5 million different foods data base can calculate the calory intake by reading the product cod bare or the meal photo. There are plenty apps working as pedometers displaying the energy consumption, but much more with games that irresistibly appeal children and teenagers. A limited screen activities time for children in primary school can prevent altering a good posture and a normal weight by keeping them in sitting position for to long. The school rhythm with a 10 minutes brake for every hour of sitting is a reliable benchmark.

\section{Conclusion}

Reducing the childhood obesity and promoting a healthy lifestyle could be the main criteria for all the decisions, actions and process related with physical and health education in kindergarten and primary school. Following this goal, the implementation of a daily program of at least one hour of organized active play outdoors could create a positive attitude towards physical activities further in life span. Physical education and active play in group is considered by most students to be a pleasant and useful activity. In such activities and through collective games children develop not only physical but also social skills besides a useful energy consumption. The daily routine prepares the body to access energy resources associated with endorphins release, creating in time the need and the willing to get outdoors and play, walk, run, and so on and so forth.

Educators and physicians can do more to encourage children and their families in working synergic for a healthy weight management through diet and physical activities combined. 


\section{REFERENCES}

1. Sahoo, K., Sahoo, B., Choudhury, A. K., Sofi, N. Y., Kumar, R., \& Bhadoria, A. S. (2015). Childhood obesity: causes and consequences. Journal of family medicine and primary care, 4(2), 187-192. doi:10.4103/2249-4863.154628

2. Eurostat 24. Noe.2011 https://ec.europa.eu/eurostat/documents/2995521 /5032782/3-24112011-BP-EN.PDF/831f0ca4-7105-4045-9e25-604141ef5108

3. Eurostat 20.Oct. 2016 https://ec.europa.eu/eurostat/documents/2995521/ 7700898/3-20102016-BP-EN.pdf/c26b037b-d5f3-4c05-89c1-00bf0b98d646

4. Raport național COSI 2017, Institutul Național de Sănătate Publică, http://insp.gov.ro/sites/cnepss/wp-content/uploads/2018/06/RAPORTNATIONAL-COSI-2017.pdf

5. Pop, C. (2013). Overweight-Cultural and Educational Aspects, Revista Românească pentru Educație Multidimensională, Volume 5, Issue2, December 2013, pp. 57-65. http://revistaromaneasca.ro/wpcontent/uploads/2014/02/ REV_Dec2013_57to65.pdf

6. Pop, C.L., Nae, I.C. (2015). Evolution of Body Mass Index in Successive Independent Samples of Romanian Young Women, Procedia ICSPEK, pp 473-476, https://scholar.google.ro/citations?user=n0yue1UAAAAJ\&hl=ro\#d= gs_md_cita-d\&u=\%2Fcitations\%3Fview_op\%3Dview_citation\%26hl \%3Dro\%26user\%3Dn0yue1UAAAAJ\%26citation_for_view\%3Dn0yue1UAA AAJ\%3AWp0gIr-vW9MC\%26tzom\%3D-120

7. Pop, C., Ciomag, R.V. (2014) The Relationship between Subjective Parameters of Well-being in a sample of Young Romanian Women, ProcediaSocial and Behavioral Sciences, vol. 149, pp. 737-740. https://doi.org/10.1016/j.sbspro.2014.08.291

8. Pop, C. (2016). Self-Esteem and Body Image Perception in a Sample of University Students. Eurasian Journal of Educational Research, 16 (64), 0-0. Retrieved from https://dergipark.org.tr/en/pub/ejer/issue/24398/258626

9. Ciomag, R.V., Filip, C. (2018).Well Being-a Balanced Life, Marathon, vol 10, no 2, pp. 47-50 https://www.ase.ro/marathon/revista/pdf/vol10/vol10_2/ 1\%20CIOMAG,\%20FILIP.pdf

10. Teodorescu, S., Popescu, V. (2015) The effects of pilates, stretching and fitness on the body composition of overweight and obese students, Medimond - Monduzzi Editore International Proceedings Division, Publishing Company Bologna (Italy), July 2015, p. 525, ISBN 978-88-7587-718-7 